\title{
ATITUDES INTOLERANTES ERGUEM MUROS E IMPEDEM A CONSTRUÇÃO DE PONTES: Uma análise cognitivo-discursiva da emersão da metáfora sistemática no gênero artigo de opinião
}

\author{
INTOLERANT ATTITUDES BUILD WALLS AND BLOCK THE CONSTRUCTION OF BRIDGES: \\ a cognitive-discoursive analysis of systematic metaphor emersion in opinion article genre
}

\author{
Ana Cristina Pelosi \\ Universidade Federal do Ceará - UFC - Fortaleza - Ceará - Brasil
}

\section{Rosangela Gabriel}

Universidade de Santa Cruz do Sul - Unisc - Santa Cruz do Sul - Rio Grande do Sul - Brasil

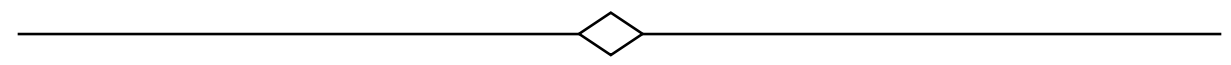

Resumo: $\mathrm{O}$ artigo apresenta resultados parciais de uma pesquisa que busca verificar como a linguagem figurada, especificamente a metafórica e a metonímica, presente em diferentes gêneros textuais tais como o literário (poema, fábula) e o jornalístico (artigo de opinião, crônica), contribui para a emergência e negociação de sentidos. A base teórico-metodológica da pesquisa advém da Teoria da Metáfora Conceptual, proposta, originalmente, por Lakoff e Johnson (1980), e expandida na década de 90 por teóricos tais como Grady (1997); e da Análise do Discurso à Luz da Metáfora, conforme a proposta de Cameron et al. (2009); Cameron e Maslen (2010). A implementação da pesquisa envolveu dois momentos. Uma primeira análise de quatro exemplares dos gêneros em investigação, segundo a metodologia da Análise do Discurso à Luz da Metáfora (ADM) e uma análise posterior, ainda a ser realizada, a partir de dados coletados por meio da interação verbal de três grupos focais compostos por alunos de uma escola estadual de Santa Maria, RS, após a leitura dos gêneros selecionados. A análise preliminar do gênero artigo de opinião revelou a presença de esquemas imagético-cinestésicos e veículos metafóricos/metonímicos estruturantes da linguagem presentes no gênero analisado e contribuiu para a comprovação da emergência da metáfora sistemática ATITUDES INTOLERANTES ERGUEM MUROS E IMPEDEM A CONSTRUÇÃO DE PONTES.

Palavras-chave: Cognição. Gênero textual. Leitura. Metáfora. Metonímia.

\begin{abstract}
The article presents partial results of a research which is aimed at verifying how figurative language, specifically metaphoric and metonymic language, present in different textual genres such as the literary and the journalistic genres, contributes to the emergence and negotiation of meaning. The theoretic and methodological basis of the research comes from Conceptual Metaphor Theory, originally proposed by Lakoff and Johnson (1980) and expanded in the 90's by theoreticians such as Grady (1997), and from Metaphor-Led Discourse Analysis (CAMERON ET AL, 2009; CAMERON; MASLEN, 2010). Research implementation involves two stages. An analysis of four exemplars of the genres under investigation according to Metaphor-Led Discourse Analysis and a second analysis, still to be carried out, of the talk of three focus groups composed by students of a state school in Santa Maria, RS, after the reading of the different genres. The preliminary analysis presented of the opinion article selected for this study reveals the presence of image-kinesthetic schemas and metaphoric/metonymic vehicles which structure the language present in the analyzed genre and contribute to the emergence of the systematic metaphor INTOLERANT ATTITUDES BUILD WALLS AND BLOCK THE CONSTRUCTION OF BRIDGES.
\end{abstract}

Keywords: Metaphor. Cognition. Textual genre. Reading. Metaphor. Metonymy. 


\section{Introdução}

A pesquisa, foco deste artigo, encontra-se em desenvolvimento. Dessa forma, o que será apresentado e discutido aqui, em termos de análise de dados, é apenas um recorte de parte do material a ser finalmente analisado. A investigação maior intitulada Leitura e cognição: Emergência $e$ negociação de sentidos pela interpretação de metáforas e metonímias em diferentes gêneros textuais busca obter um melhor entendimento da relação entre linguagem, cognição e cultura por meio da análise do papel que a linguagem figurada, especificamente a metafórica e a metonímica, estruturadas a partir de esquemas imagéticocinestésicos, desempenha na emergência de sentidos decorrentes da leitura de textos pertencentes a diferentes gêneros.

Com esta preocupação em pauta, nos apoiamos teórica e metodologicamente em pressupostos vinculadas à Linguística Cognitiva (LC) e à Linguística Aplicada (LA). Subjacente a tais abordagens teóricas, entendemos, segundo a Teoria dos Sistemas Dinâmicos Complexos (SDC), que a linguagem, seja ela figurada ou não, constitui-se como um sistema complexo. Assim, as emergências discursivas não podem ser consideradas linearmente, mas, resultam de interações dinâmicas que se adequam a acoplamentos e adequações de múltiplas escalas (níveis), internos e externos ao discurso. Em linha com Cameron e Maslen (2010, p. 84), entendemos o discurso, tanto aquele que emerge em interações de fala-pensamento-fala quanto o que emerge na escrita de um texto como "um conjunto interconectado de sistemas complexos e subsistemas que operam em várias escalas de tempo e níveis de organização social".

Especificamente, sob o aporte da LC, nos interessa a Teoria da Metáfora Conceptual (TMC), vinculada às propostas de Lakoff e Johnson (1980, 1999) e Grady (1997) a respeito da natureza neurobiológica da metáfora. A vertente que nos liga à LA centra-se na proposta da Análise do Discurso à Luz da Metáfora (ADM), conforme a proposta de
Cameron et al. (2009), Cameron e Maslen (2010). Utilizamos os critérios teórico-metodológicos da LC e ADM, tanto nas análises dos exemplares dos gêneros textuais (artigo de opinião, crônica, fábula e poema) realizadas na primeira etapa da pesquisa quanto na segunda etapa, que envolve a análise das falas e produções escritas dos alunos participantes da pesquisa, a partir da leitura de tais gêneros.

Uma de nossas preocupações é a de compreender os processos cognitivos e culturais, em especial os referentes à linguagem metafórica, envolvidos na emergência de sentidos viabilizados pela leitura de textos pertinentes aos gêneros sob investigação. Acreditamos que um texto possa fazer emergir diferentes sentidos. Isso se dá porque processos cognitivos atrelados a histórias de vida diferenciadas, além de fatores de ordem social e cultural, exercem influência sobre a emergência de sentidos a partir da leitura. Entendemos a possibilidade de leituras conotativas, viabilizadas por meio da utilização de linguagem metafórica em textos, como um dos principais modos em que se dá a emergência de sentidos. Dessa forma, consideramos a metáfora, não como mero ornamento linguístico, mas, segundo Lakoff e Johnson (1980, 1999), como figura de pensamento. Mas, não somente, posto que acreditamos que antes de mera instanciação de conceitos (mapeamentos) na mente, a metáfora se encontra a serviço dos processos cognitivo-discursivos, que se engendram a partir de possíveis leituras de um texto. Assim, ao contrário de ser uma opção, ornamento, recurso poético ou estilístico - conforme a visão tradicional - é um meio de organização, de compreensão da realidade e de produção cognitiva capaz de exercer papel crucial na veiculação não só de sentidos diretamente ligados a um texto, como da emergência e negociação de outros sentidos a partir de leituras plausíveis (ou possíveis) engendradas por um sujeito dotado de uma cognição corpórea, socioculturalmente situada.

Lançadas as bases teórico-metodológicas da investigação, expomos a seguir, de forma mais detalhada, nossas questões de pesquisa, objetivos, referencial teórico, metodologia, além de uma análise 
preliminar de um dos textos que compõem o exemplário utilizado na pesquisa.

\section{Questionamentos}

Nossa preocupação maior volta-se para a investigação de como a linguagem metafórica presente em diferentes gêneros textuais promove, a partir da atuação linguístico-cognitiva do indivíduo, o engendramento de outros sentidos atrelados direta ou indiretamente aos temas presentes em textos lidos, e como tais sentidos emergem nas suas interações faladas e escritas. Acreditamos que a leitura sirva de mote para a emergência de metáforas conceptuais (MCs) ou sistemáticas (MSis) estruturadas a partir de esquemas imagético-cinestésicos (EICs) e de fatores sociais e culturais compartilhados pelos grupos de participantes da pesquisa. Cremos, também, que o engendramento nas falas de veículos metafóricos (VMets) e metonímias (Metons) direta ou indiretamente relacionadas aos tópicos discursivos (TDs), presentes no texto lido ou ainda outros possibilitados pela leitura do texto, possam conduzir a MSis que traduzam ideias, crenças, valores, atitudes pertinentes a vivências individuais ou comuns aos participantes da pesquisa. Uma segunda preocupação é verificar se é possível traçar paralelos entre as análises realizadas pela pesquisadora (identificação de EICs, MCs, VMets, Metons e MSis) dos textos pertencentes aos diferentes gêneros textuais com os dados colhidos a partir da produção linguística dos alunos. Finalmente, interessa-nos verificar se o grau de escolaridade, no caso da presente pesquisa, alunos do primeiro ao terceiro ano do ensino médio, influencia positivamente no desempenho dos participantes no que diz respeito à produção de linguagem figurada nas falas e nos materiais escritos produzidos a partir dos gêneros textuais aos quais foram expostos.

\section{Objetivos}

O objetivo principal da investigação é identificar a linguagem figurada, especificamente, a metafórica e a metonímica, presente em gêneros textuais tais como o jornalístico (artigo de opinião, crônica) e o literário (fábula, poema), verificando como esta linguagem contribui para a emergência de sentidos vinculados direta ou indiretamente ao texto lido. Atrelado a este objetivo, queremos também analisar os sentidos metafóricos emergentes nas falas e produções escritas dos alunos participantes da investigação, buscando compreender aspectos individuais ou compartilhados de sentimentos e atitudes ali expressos.

Com este objetivo maior em mente implementamos até o momento no conjunto de textos selecionados para análise, os seguintes objetivos: 1) identificamos os EICs e MCs estruturadas a partir de tais esquemas; 2) buscamos analisar como fatores socioculturais contribuem para a emergência das metáforas presentes nos textos analisados; 3) verificamos como VMets e Metons contribuem para a emergência de metáforas sistemáticas presentes em tais gêneros.

Após a conclusão da pesquisa de campo, as falas motivadas pela atividade leitora dos alunos participantes da pesquisa serão submetidas aos passos 1 a 3, acima descritos. Além desses, um quarto objetivo a ser implementado partir da análise dos dados colhidos pela condução dos grupos focais ${ }^{1}$ será buscar entender que ideias, crenças e atitudes permeiam suas falas e produções escritas, averiguando como as técnicas utilizadas (interações verbais em grupos focais e a escrita de um comentário a respeito de um dos textos lidos) favoreceram a compreensão dos temas abordados nos e a partir dos textos lidos. Nosso objetivo, portanto, não é o de verificar ou de algum modo mensurar objetivamente a compreensão leitora dos gêneros textuais lidos e discutidos pelos alunos participantes do estudo, mas, do ponto de vista da visão dinâmica do discurso, analisar como, a partir da

\footnotetext{
1 Um grupo focal caracteriza-se como um grupo de pessoas reunidas para discussão de um tema, objeto da pesquisa, a partir de suas experiências pessoais. Segundo Gatti (2012) é uma técnica que vem sendo cada vez mais utilizada em abordagens qualitativas nas ciências sociais. Maiores informações serão fornecidas na seção sobre os procedimentos metodológicos.
} 
leitura desses gêneros, sentidos (metafóricos ou não) diretamente atrelados a ela ou dela emergentes podem contribuir para tornar a atividade leitora produtiva, contribuindo assim na formação de leitores engajados e críticos.

Finalmente, o quinto e sexto objetivos, ainda a serem implementados, envolverão, respectivamente, comparações das análises realizadas pela pesquisadora dos textos do exemplário com os resultados obtidos a partir das produções dos alunos participantes da pesquisa, bem como comparações das produções dos próprios alunos pertencentes aos três grupos formados por alunos pertencentes aos três anos do ensino médio. Desejamos assim verificar se, nas falas, os alunos deixam emergir EICs, expressões metafóricas ou metonímicas estruturadas conceptualmente por tais esquemas, além de VMets e Metons iguais ou semanticamente semelhantes aos identificados pela pesquisadora e se um maior grau de escolaridade influi positivamente na produção metafórica oral e escrita dos participantes, a partir da leitura e discussão de textos pertencentes a diferentes gêneros.

\section{Referencial teórico}

A visão filosófica clássica da relação entre linguagem e realidade tem, tradicionalmente, promovido a ideia de que estas duas entidades se associam numa relação de pareamento, de modo que a linguagem nada mais seria do que um meio de rotulagem da realidade, que viria pronta com significados estanques, intrínsecos à natureza dos objetos no mundo. Com a visão cognitiva da metáfora, lançada por Lakoff e Johnson em 1980 e expandida na obra Philosophy in the Flesh, dos mesmos autores, publicada em 1999, este posicionamento teve seus alicerces abalados. Sua teoria rompeu com as asserções do Objetivismo, como denominaram estes autores, o conjunto de pressupostos filosóficos e crenças veiculados pela tradição filosófica ocidental, grandemente apoiada na filosofia analítica anglo-saxônica.
Na contramão da visão objetivista, os referidos autores promoveram uma visão experiencialista do significado e da formação conceptual, na qual o significado deixa de ser entendido como conjunto de traços essenciais das coisas (visão essencialista da linguagem) passando a ser considerado como uma emergência dinâmica de um conjunto de fatores biopsicológicos e socioculturais. Apenas para exemplificar, o traço "ser lilás", que poderá caracterizar a cor de uma peça de vestimenta, não se impõe como um traço essencial e suficiente do objeto, mas decorre do modo como o olho humano processa as cores, e de fatores externos tais como a incidência ou não de luz sobre o objeto, para que a impressão registrada no cérebro seja a cor lilás. Mudem-se as condições (por exemplo, variações de intensidade ou qualidade da luz) nas quais a peça de vestimenta é apresentada e já não se teria a mesma percepção da cor.

Assim, no paradigma experiencialista, os significados atrelados à nossa conceptualização do mundo decorrem primordialmente de interações com o ambiente ecológico e sociocultural e das formas de ver e entender o mundo.

Conforme Lakoff e Johnson (1999, p. 44),

[...] nossos conceitos não podem ser reflexos diretos de uma realidade externa, objetiva, abstraída da mente, visto que nosso sistema sensório-motor desempenha um papel crucial em modelá-los. Por outro lado, é o envolvimento do sistema sensório-motor no sistema conceptual que o mantém em contato próximo com o mundo. (Tradução nossa.) ${ }^{2}$

Crucial para o entendimento de como se dão as inter-relações entre cérebro/mente/corpo/mundo na emergência de conceitos, é considerarmos o que propõe a Teoria dos Sistemas Dinâmicos Complexos (SDC). Tal abordagem, originária da matemática, tem sido aplicada na explicação de sistemas biológicos e, mais recentemente, em áreas das ciências humanas

\footnotetext{
2 "[...] our concepts cannot be a direct reflection of external, objective, mind-free reality because our sensorimotor system plays a crucial role in shaping them. On the other hand, it is the involvement of the sensorimotor system in the conceptual system that keeps the conceptual system very much in touch with the world." (LAKOFF e JOHNSON, 1999, p. 44)
} 
e sociais, conforme estudos já desenvolvidos sobre linguagem (ELMAN, 1995; STEELS, 2000), desenvolvimento cognitivo e linguístico (VAN GEERT, 1998), linguística aplicada (LARSEN-FINNEGAN; CAMERON, 2008), psicologia do desenvolvimento (THELEN; SMITH, 1994, THELEN, SCHONER, SCHEIER; SMITH, 2001) e ciências sociais (TURNER, 2002). Segundo a teoria, um sistema complexo é composto de muitos tipos diferentes de agentes ou elementos que interagem dinamicamente por meio de diferentes tipos de relações e conexões. É dito complexo, não somente devido à multiplicidade de elementos e conexões entre os componentes do sistema, mas pelas mudanças que constantemente ocorrem nas relações entre seus elementos, o que resulta em mudanças, auto-organizações e emergências.

Ou seja, sistemas complexos não são sistemas fechados, autocontidos. Estão abertos a novas energias e interagem com elementos externos e internos a eles próprios, estando altamente propensos a mudanças. É dessa instabilidade que decorrem adaptações e evoluções, o que equivale a dizer que a estrutura se adequa dinamicamente ou muda a ponto de fazer emergir um novo sistema. Mudanças podem ocorrer de forma suave e contínua ou podem ser repentinas à medida que o sistema muda de comportamento.

Acreditamos que para uma investigação adequada dos modos como os sentidos emergem em diferentes gêneros tais como o jornalístico, o literário e o poético, para citar apenas os que compõem o exemplário da pesquisa aqui parcialmente relatada, se faz necessário entender linguagem, cognição e cultura como sistemas dinâmicos que se mesclam e se adaptam para fazer emergir significados possibilitados, dentre outros recursos, pela figuratividade.

Assim, o indivíduo dotado de uma cognição corpórea socioculturalmente situada, atrela sentidos a um dado texto (seja oral ou escrito) a partir de valores, crenças e atitudes compartilhados entre os membros de uma comunidade. Visto que o processo de compreensão textual se deve em parte, à capacidade de compreender metáforas, precisamos compreender a linguagem de modo geral e, especificamente, a linguagem figurada (para fins da presente investigação - metáforas e metonímias) que incorporam imagens, esquemas corpóreos, gestos, como elementos integrantes de sistemas sociocognitivos complexos nos quais fatores neurofisiológicos, psicológicos, linguísticos, socioculturais e ecológicos interagem dinamicamente.

Cameron (2007), uma das autoras que nos serve de suporte teórico e metodológico, aborda questões ligadas à emergência de metáforas no discurso sob a perspectiva dos SDC. Segundo ela, para se compreender a metáfora, é necessário entendê-la no seu uso dialógico como parte integrante do uso da língua, por sua vez, igualmente entendida como sistema dinâmico complexo e não como instanciação de uma competência fixa e preexistente. De modo que nas interações orais, o fluxo discursivo ocorre como um processo de pensamento-e-fala, em que o uso de hifens na expressão indica, segundo Cameron (2003), LarsenFreeman e Cameron (2008), a inseparabilidade entre pensamento e linguagem.

Pensamento-e-fala é um processo dinâmico que requer a interpretação constante por parte dos participantes da palavra do outro e o ajuste a partir dessa compreensão à medida que intenções e emoções evoluem no fluxo do discurso. Nessas situações de trocas, o tipo de evento discursivo pode influenciar a forma linguística utilizada, o que, por sua vez, pode influenciar o modo como ideias são descritas. Cognição e linguagem não podem, portanto, ser consideradas elementos estanques, separáveis. Esta tese considera as emergências metafóricas, identificáveis no discurso, como um processo dinâmico em constante mudança, decorrente tanto de fatores cognitivos, socioculturalmente situados, bem como de fatores linguísticos que se imbricam e se complementam. Percebe-se que essa concepção permite entender a metáfora mais do que como uma figura do pensamento instanciada a partir de mapeamentos entre domínios fonte e alvo. Isso não implica dizer 
que rejeitemos a natureza conceptual da linguagem metafórica, contudo, acreditamos que mais do que expressões linguísticas licenciadas por mapeamentos conceptuais na memória de longo prazo, a metáfora é algo dinâmico, mutável a mercê de elementos internos e externos aos usuários da língua, imersos em sistemas de diversas naturezas (biológicos, psicológicos, socioculturais, ecológicos etc.).

A metáfora é entendida aqui nem somente como mapeamento estanque (um conceito) armazenado na mente, nem meramente como algo que se constitui unicamente no fluxo do discurso, ou seja, consideramos a metáfora como resultante de um processo dinâmico que envolve um caminho de mão dupla nos sentidos cognição-discurso, discursocognição. Com isso, queremos dizer que emergências metafóricas no âmbito textual-discursivo resultam de processos tanto de ordem cognitiva quanto de contingências atreladas ao contexto de produção discursiva.

A seguir, dada a limitação de espaço, discorremos sobre cada um dos aportes teóricos que norteiam a pesquisa aqui reportada.

Abordamos primeiramente, os esquemas de imagem e movimento (Cf. LAKOFF, 1987; JOHNSON, 1987) e a Teoria da Metáfora Primária (Cf. GRADY, 1997; LAKOFF; JOHNSON, 1999) que se constitui numa expansão à TMC originalmente proposta em 1980, para, em seguida, focar nossa atenção no conceito de metáfora sistemática, conforme Cameron, 2003; Cameron et al. 2009; Maslen e Cameron, 2010.

Lakoff (1987) e Johnson (1987) postulam que o significado emerge das experiências de natureza sensoriomotoras que o indivíduo mantém com o ambiente que o cerca, ao longo de seu desenvolvimento cognitivo. No processo de interação com seu meio circundante, a criança internalizaria, a partir das primeiras atuações corpóreas e manipulações de objetos, estruturas pré-conceituais chamadas esquemas imagético-cinestésicos. Segundo Johnson (1987, p. 29)

[...] para que possamos ter experiências conectadas e significativas, sobre as quais sejamos capazes de compreender e raciocinar a respeito, deve haver um padrão e ordem para nossas ações, percepções e concepções. Um esquema é um padrão recorrente em termos de forma e regularidade nestas, ou destas atividades de ordenação contínua. Tais padrões emergem como estruturas significativas para nós, certamente, ao nível de nossos movimentos corporais no espaço, de nossa manipulação com os objetos, e de nossas interações perceptuais" (JOHNSON 1987, p. 29). (Tradução nossa.) $^{3}$

O termo imagético se refere a imagens de diferentes naturezas que se constituem a partir de variados inputs: visuais, olfativos, gustativos, tácteis, auditivos e envolvem também movimentos e ações. Alguns exemplos de EICs são: RECIPIENTE, LIGAÇÃO, PERCURSO/CAMINHO, CENTRO/PERIFERIA, FORÇA, EQUILÍBRIO, PARTETODO, ORIENTAÇÃO FRENTE-TRÁS ${ }^{4}$ etc. Na explicação fornecida pela LC, processos de transformação e abstração de esquemas estão na base das formações metafóricas que, como parte integrante da cognição humana, se manifestam na linguagem e não requerem qualquer esforço cognitivo para sua compreensão. Assim, por exemplo, se dizemos: "Ela não tem nada na cabeça" ou "Minha cabeça está cheia de ideias", o fazemos porque a linguagem metafórica utilizada nestas sentenças é estruturada a partir do esquema de RECIPIENTE, que permite a compreensão de "cabeça" em termos de um recipiente que pode estar cheio ou vazio. $A$ metáfora VIDA É VIAGEM, por sua vez, fortemente entrincheirada na cultura ocidental, teria como parte de seu domínio-fonte o esquema de PERCURSO/CAMINHO.

\footnotetext{
3 “[...] in order for us to have meaningful, connected experiences that we can comprehend and reason about, there must be pattern and order to our actions, perceptions, and conceptions. A schema is a recurrent pattern, shape, and regularity in, or of, these ongoing ordering activities. These patterns emerge as meaningful structures for us chiefly at the level of our bodily movements through space, our manipulation of objects, and our perceptual interactions." (JOHNSON 1987, p. 29).

${ }^{4}$ Os termos estão digitados em caixa alta, fonte 12 por ser esta a notação, costumeiramente, utilizada na LC, para conceitos, metáforas e metonímias. As MSis são, além disso, apresentadas em itálicos por ser esta a notação na Análise do Discurso à Luz da Metáfora (ADM). Ver Cameron, Low e Maslen (2010, p. 117).
} 
$\mathrm{Na}$ visão da LC, as experiências sensóriomotoras, internalizadas na forma de esquemas de imagem e movimento (esquemas imagéticocinestésicos), estão na base de nossos conceitos e estruturam grande parte da linguagem, motivando as estruturas lexicais, o processo de gramaticalização, os processos metafóricos e metonímicos etc. Acreditamos que esquemas de imagem e movimento estruturem parte significativa das formas linguísticodiscursivas pertinentes aos diferentes gêneros textuais investigados. A investigação aqui parcialmente relatada busca explicar como tais esquemas viabilizam o surgimento de elementos cognitivo-discursivos da linguagem nos gêneros analisados, assim como nas falas e produções escritas dos participantes da pesquisa.

Outra teoria afeita à LC que, desde a década de 90, se apresenta como um avanço à tese de Lakoff e Johnson lançada em 1980 é a Teoria da Metáfora Primária (TMP), proposta por Grady (1997), Christopher Johnson (1999), Narayanan (1997) e Fauconnier e Turner (1998). Essa teoria nos serve de suporte, visto acreditarmos que a linguagem metafórica presente nos gêneros que compõem o exemplário da pesquisa emerja, em parte, de aspectos cognitivos afeitos a tais metáforas. De fato, conforme reconhecem Grady (1997); Lakoff e Johnson (1999), as metáforas primárias (MPs) estão na base de metáforas complexas (ou compostas), mais fortemente influenciadas pela cultura. As MPs seriam como "unidades atômicas" que juntas formariam "moléculas" - as já mencionadas metáforas complexas.

Segundo os teóricos citados, as MPs, são tipos de metáfora mais primitivos, de base neural, que envolvem a correlação entre domínios de naturezas diversas - um perceptual (fonte) e um conceptual (alvo), que se coativam a partir das interações com o mundo e das experiências perceptuais com as quais temos contato desde a mais tenra idade. Os circuitos neurais envolvidos nos mapeamentos entre domínios fonte e alvo de tais metáforas se constituem a partir da integração de experiências recorrentes e coocorrentes, a partir da resposta cognitiva a experiências de natureza perceptual. Os conceitos pertinentes aos domínios fonte das MPs envolvem algum tipo de conteúdo ligado a percepções ou sensações. Portanto, se caracterizam por terem conteúdo de imagem, estando na base de representações mentais que emergem a partir de tais experiências. Os conceitos primários relativos aos domínios alvo são, no entanto, desprovidos de imagem e, assim, não se constituem como percepções diretas de experiências. São, de fato, respostas a operações ou funções de tais experiências - o resultado de operações cognitivas básicas, às quais, possivelmente, não tenhamos acesso direto, ainda que possam informar e motivar nossas ações (cf. GRADY, 1997).

Por termos os mesmos tipos de estruturas neurofisiológicas e cognitivas e experienciarmos as mesmas situações ou situações semelhantes, ao longo do desenvolvimento cognitivo, os proponentes da hipótese da metáfora primária sugerem que tais metáforas tenderiam à universalidade. Seriam elas que nos possibilitariam entender sem qualquer tipo de esforço consciente expressões do tipo: "Ela é uma pessoa fria"; ou "Eles são muito próximos", e ainda "Vejo qual é o problema" etc. Segundo a hipótese estas são, respectivamente, instanciações linguísticas das MPs "AFETO É CALOR"; "INTIMIDADE É PROXIMIDADE FÍSICA" E "SABER/ENTENDER É VER".

A TMP nos parece uma teoria viável na explicitação de uma base sensório-motora para boa parte dos conceitos metafóricos que formamos ao longo de nosso desenvolvimento cognitivo e que, acreditamos, estrutura e nos possibilita compreender, sem esforço cognitivo especial, parte da linguagem metafórica que, num processo descendente (topdown), portanto, da cognição para o discurso possa emergir em gêneros textuais (discursivos). Obviamente, visto que o desenvolvimento conceptual ocorre em contextos socioculturalmente determinados e por serem nossas estruturas neurais elementos integrantes de sistemas complexos dinâmicos, abertos à influência de agentes diversos, as coativações entre domínios de natureza sensorial e 
cognitiva, engramadas na memória de longo prazo, que constituem as metáforas primárias podem sofrer influências de ordem sociocultural (Cf. MACEDO, 2007).

Nesse sentido, parece-nos razoável supor que a linguagem figurada, em especial a metafórica e a metonímica, presente em gêneros textuais resulte, entre outros fatores, de um processo que consideramos uma via de mão dupla (cogniçãodiscurso-cognição). Dessa forma, cremos que não somente processos de natureza descendente (cognição-discurso), mas também de natureza ascendente (discurso-cognição) operem na emergência da linguagem instanciada nos diversos gêneros textuais (discursivos). Por isso, passamos agora a discorrer a respeito do conceito de Metáfora Sistemática (MSis), que emerge a partir de constrangimentos textuais-discursivos, conforme proposto por Cameron (2007); Cameron et al. (2009); Cameron e Maslen (2010).

Segundo os autores citados, a MSis é de natureza discursiva visto que emerge na e a partir da interação que se estabelece entre os participantes do discurso. Nessa perspectiva, essa metáfora é vista como um fenômeno multifacetado e dinâmico. As metáforas, assim como o discurso, são entendidas como movimentos ou emergências tanto linguísticas quanto cognitivas. (LARSEN-FREEMAN; CAMERON, 2008; CAMERON et al., 2009). Para Cameron (2010), as MSis emergem a partir de agrupamentos de VMets - termos ou expressões utilizados com sentido incongruente com seu significado mais concreto/experiencial - interligados e usados em torno de um mesmo tópico durante um evento discursivo ${ }^{5}$. Assim, tais metáforas são propostas como um passo metodológico reflexivo do pesquisador, a partir do uso de diferentes metáforas linguísticas (idênticas ou semanticamente relacionadas) de forma sistemática ou recorrente ao longo do evento discursivo e ligadas a um mesmo

\footnotetext{
${ }^{5}$ Eventos discursivos são as atividades de linguagem que se dão no tempo e em determinados ambientes discursivos, através de gêneros textuais constituídos de modalidades discursivas e de sequências textuais, envolvendo interlocutores determinados, com objetivos específicos (MARCUSCHI, 2000).
}

tópico ou a tópicos relacionados no discurso emergente $^{6}$. (CAMERON, 2010).

São sistemáticas no sentido de serem recorrentes e indicarem que os participantes da interação estão ativando algum tipo de conceptualização mental que, em termos corpóreos e socioculturais, liga-se a ideias, crenças, atitudes ou mesmo a modos de compreender a realidade em torno do tópico discursivo instanciado no gênero em análise.

Essa abordagem da metáfora se opõe àquela defendida pela TMC, pois, embora as MSis tenham base cognitiva, são realizações linguísticas anteriores à representação mental de conceitos metafóricos. Nessa visão, mais central para a compreensão e análise da metáfora, são as expressões metafóricas que emergem no discurso e não supostos mapeamentos conceptuais subjacentes a tais emergências.

Embora compartilhemos das ideias de Cameron et al. (2009); Cameron e Maslen (2010), não descartamos a possibilidade de que tais emergências metafóricas (i.e. metáforas sistemáticas), se constituam a partir de um processo complexo, dinâmico e automático, parte do nosso inconsciente cognitivo. Assim, acreditamos que tais metáforas se formem num processo viabilizado numa dupla direção - da cognição para o discurso e igualmente, do discurso para a cognição.

A proposta por nós defendida requer sua associação às ideias propostas pela TMC, na sua versão mais atual, ou seja, a proposta defendida por Grady (1997), Christopher Johnson (1999); Narayanan (1997) e pelos próprios Lakoff e Johnson, em Philosophy in the Flesh (1999), embora consideremos os constrangimentos impostos pelo contexto textual discursivo. Por outro lado, a proposta teórica de Cameron para o estudo da metáfora nos

\footnotetext{
${ }^{6}$ Embora Cameron e colegas não se detenham em considerar o papel da metonímia na emergência da metáfora sistemática, acreditamos que a inter-relação metáfora-metonímia seja muitas vezes central para a emersão de uma MSis. Com base no aporte cognitivo-discursivo, consideramos metonímias (Metons) emergências nas quais relações tais como parte/todo, local/evento, contentor/conteúdo etc. simbolizam todo um domínio cognitivo envolvendo ações, situações, acontecimentos que podem ser evocados a partir do uso da palavra ou expressão metonímica.
} 
parece importante como recurso teórico-analítico, para a condução das análises do papel da linguagem metafórica na compreensão e na emergência de sentidos direta ou indiretamente decorrentes dos gêneros textuais analisados.

\section{Metodologia}

A pesquisa se desenvolve em dois estágios. $O$ primeiro momento envolveu a busca por textos pertencentes a diferentes gêneros textuais, em sites de quatro jornais online de grande circulação nacional (Jornal do Brasil, do Rio de Janeiro; O Estado de São Paulo; O Povo, de Fortaleza-Ceará e Zero Hora, da rede RBS, Rio Grande do Sul), blogs e livros de poemas de Carlos Drummond de Andrade. A busca resultou na reunião de 70 textos que foram salvos em pastas de arquivos docx, categorizados segundo seus gêneros. Dentre os textos reunidos nos corpora, selecionamos, após análise do conteúdo dos vários arquivos, um exemplário constante de quatro textos (artigo de opinião, crônica, fábula e poema) para serem analisados e posteriormente, aplicados aos alunos participantes da pesquisa.

Os textos foram salvos em formato RTF, em linhas numeradas. Em seguida, foram lançados no Atlas.ti (Computer-Assisted Qualitative Data Analysis Software), um programa desenhado pela Universidade Técnica de Berlin para auxiliar na organização, codificação e agrupamento de dados em categorias de análise possibilitando a operacionalização de análises sob a forma de textos, imagens e áudios.

A seguir, relatamos os procedimentos analíticos e resultados preliminares da análise realizada sobre um dos textos, no caso, o artigo de opinião intitulado "Os Muros", de Selvino Heck, publicado no Jornal do Brasil em 16/11/2014, na seção Sociedade Aberta.

Não descartamos, conforme já salientado, a base cognitiva da linguagem (figurada/não figurada) de modo geral e, portanto, acreditamos que a emergência da metáfora se dê bidireccionalmente, envolvendo cognição e discurso sem predominância de um sobre o outro. Nosso foco é, no entanto, apontar para uma das possíveis MSis no discurso emergente a partir da leitura do texto supracitado. Apesar do foco da análise estar no discurso, em linha com nosso posicionamento que entende a linguagem figurada em geral como emergência cognitivodiscursiva, identificamos no processo analítico, EICs e MCs que igualmente podem ter contribuído para a emergência da MSis. Segundo a proposta da ADM, procedemos, num primeiro momento, à identificação dos TDs e à codificação e agrupamentos em categorias de análise dos VMets e Metons empregados pelo autor do texto, ao discorrer sobre um mesmo tópico, ou tópicos relacionados. Finalmente, a partir da reflexão em torno dos VMets buscamos identificar possíveis MSis.

\section{Análise e resultados preliminares}

Apresentamos a seguir a análise e os resultados preliminares referentes ao artigo de opinião "Os Muros". Da análise destacamos apenas a MSis ATITUDES INTOLERANTES ERGUEM MUROS E IMPEDEM A CONSTRUÇÃO DE PONTES, identificada no artigo de opinião analisado neste trabalho.

Para maior clareza, a MSis identificada no texto analisado é apresentada a partir de um roteiro adaptado da metodologia de sistematização e apresentação de dados utilizada por Carneiro (2014). O roteiro inclui: (1) Número de ordem; (2) Título; (3) Total de excertos envolvidos; (4) Linhas inicial e final de cada um dos excertos, marcando os momentos de estabilização da MSis; (5) Total de TDs envolvidos; (6) Total de MetVs, (7); Total de Metons; (8) Total e tipos de mudanças metafóricas envolvidas.

O quadro sinótico apresentado antes da análise da MSis em pauta, permite que os detalhes relativos à metáfora sejam apresentados de forma condensada. Logo após a apresentação do quadro, a análise é apresentada excerto a excerto. 
Quadro 1: ATITUDES INTOLERANTES ERGUEM MUROS E IMPEDEM A CONSTRUÇÃO DE PONTES

\begin{tabular}{|c|c|c|c|c|}
\hline EXCERTOS & $\begin{array}{c}\text { TÓPICOS } \\
\text { DISCURSIVOS }\end{array}$ & $\begin{array}{c}\text { VEÍCULOS } \\
\text { METAFÓRICOS }\end{array}$ & METONÍMIAS & $\begin{array}{c}\text { TIPOS DE } \\
\text { MUDANÇAS } \\
\text { METAFÒRICAS }\end{array}$ \\
\hline (I.01 a 15) & TD1: Muros e divisões & 11 & 00 & $\begin{array}{c}\text { Repetição } \\
\text { Relexicalização }\end{array}$ \\
\hline (I.16 a 18) & $\begin{array}{c}\text { TD2: Isolamento } \\
\text { imposto por muros } \\
\text { simbólicos ou literais. }\end{array}$ & 02 & 05 & $\begin{array}{l}\text { Explicação } \\
\text { Contraste } \\
\text { Literalização }\end{array}$ \\
\hline (I.33 a 37). & $\begin{array}{l}\text { TD4: Domínio dos ricos } \\
\text { sobre os pobres }\end{array}$ & 03 & 03 & \\
\hline TOTAL: 05 & 03 & 16 & 08 & 05 \\
\hline
\end{tabular}

Fonte: Adaptado de Carneiro (2014, p. 134)

A emergência de VMets no fluxo discursivo, quer em textos escritos quer em interações faladas, ocorre segundo o que Cameron (2010, p. 89, 90) chama de desenvolvimento do veículo (vehicle development) que abrange quatro movimentos, conforme segue: 1. Repetição (uso do mesmo termo na sua forma original ou transformada); 2. Relexicalização (uso de sinônimos próximos ou equivalentes ao termo utilizado originalmente); 3. Explicação (elaboração, explanação ou expansão do termo); 4. Contraste (uso de um termo contrastante ou antônimo).

Conforme o quadro acima, alguns desses recursos são empregados ao longo do texto analisado, evidenciando a evolução e emergência da metáfora ATITUDES INTOLERANTES ERGUEM MUROS

\section{E IMPEDEM A CONSTRUÇÃO DE PONTES.}

O primeiro movimento rumo à emersão da metáfora ocorre logo no início do texto e envolve quatro TDs (Muros e divisões, Isolamento imposto por muros simbólicos ou literais, Demolição de muros e necessidade de construção de pontes e Domínio dos ricos sobre os pobres), 16 VMets e 08 Metons, conforme destacado nos excertos a seguir.

\section{Excerto 1}

TD1: Muros e divisões

01. "Precisamos de pontes, não de $\underline{\text { muros", disse }}$ o papa Francisco há poucos dias.

02. O Muro de Berlim caiu há 25 anos. Era um muro que dividia uma cidade, dividia

03. uma população, dividia um país.

04. Mas, os muros caíram de fato nas últimas décadas? Ou, quais muros mais precisam

05. cair urgentemente? Acabamos de sair de uma eleição no Brasil, onde, além dos

06. debates e divergências políticas normais e necessárias, muros foram erguidos.

07. Brasileiros disseram que iriam sair do país dependendo do resultado da eleição.

08. Houve quem pregasse a divisão do país: que se separassem pobres e nordestinos do

09. Sul e Sudeste por causa do seu voto majoritário a favor de uma candidata, que 10. aqueles ficassem nos seus guetos e na sua "má consciência". Afinal, pobres e

11. nordestinos são desinformados, não sabem votar, como falou um ex-presidente da 12. República.

13. Muros de preconceito, discriminação, falta de diálogo, racismo, homofobia,

14. violência têm sido erguidos à farta em muitos ambientes e no conjunto

15. da sociedade. 
O fluxo discursivo que leva à emersão da MSis tem início nas primeiras linhas do texto com a inclusão da citação das palavras do Papa Francisco "Precisamos de pontes não de muros", tema central da linha de argumentação desenvolvida pelo autor, (I. 1). A base cognitiva para tal afirmação parece apoiarse em dois esquemas de imagem e ação (EICs), o de ligação e o de força que permeiam o texto como um todo. Enquanto "pontes" aproximam e vencem os espaços que separam pessoas por vários motivos, gerando intolerância e distanciamento (separação) por parte de grupos dominantes da sociedade, detentores do poder em relação a grupos dominados, mais fracos; muros, por outro lado, efetivam tal separação por estabelecerem barreiras/bloqueios que representam a força contrária à aproximação entre semelhantes. Muros simbolizam fronteiras entre recipientes que estabelecem limites/barreiras (limitações) a indivíduos, posto que, por estarem contidos por "muros" (literais ou não), as pessoas têm seus movimentos, sua liberdade, sua movimentação tolhida, como que por uma força que as impede de se movimentarem livremente. Os embates entre momentos ora de maior aproximação, ora de maior distanciamento são trazidos à tona por meio de VMets de repetição e expansão introduzidos pela pergunta: "os muros caíram de fato?...ou quais muros precisam cair urgentemente"? (I. 4, 5), para a seguir admitir, devido a divergências e impasses políticos nas últimas eleições presidenciais, que "muros" fossem, na realidade erguidos. (I. 6), o que resultou em que alguns pregassem "a separação entre pobres e nordestinos do resto do Sul e Sudeste". (I. 8, 9). O próximo movimento rumo à emersão da metáfora ocorre na linha 13, na qual os VMets de repetição e explicação por expansão do veículo "muros" são novamente utilizados, "muros de preconceitos...falta de diálogo, racismo, homofobia, violência têm sido erguidos".

O excerto 2 (I. 16 e 19), a seguir, reitera o tema central por destacar a situação de isolamento físico e simbólico instaurado por muros, sejam esses literais ou não. Nessas linhas, além das mudanças metafóricas já listadas (i.e. repetição, explicação e contraste) utilizadas durante períodos de desequilíbrio do discurso, identificamos outro uso denominado por Cameron (2008) de literalização (i.e. um item lexical tem o sentido simbólico (metafórico) carregado para seu sentido literal). O autor dá exemplos de vidas (pessoas) segregadas de vários modos. Literalmente isoladas, separadas por muros dos condomínios onde vivem, mas, igualmente segregadas por questões políticas, religiosas e sociais como quando escreve "Palestinos estão cercados de muros. Mexicanos estão cercados de muros. (I. 19). Parece, contudo, haver nesse uso repetido do mesmo VMet "cercados por muros" uma interação entre metonímia e metáfora, posto que uma parte do domínio cognitivo de objetos que podem causar isolamento, impedir aproximação tais como muros e cercas foram de fato erguidos nas fronteiras de tais países, contudo, por expansão metafórica, passam a simbolizar divisões instauradas por questões ideológicas.

\section{Excerto 2}

TD: Isolamento imposto por muros simbólicos ou não

16. Muros cercam cada vez mais casas, jardins, mansões e condomínios, onde ninguém

17. consegue entrar. São ilhas sem acesso, a não ser para seus privilegiados moradores

18. ou os trabalhadores a seu serviço.

19. Palestinos estão cercados de muros. Mexicanos estão cercados de muros.

O terceiro e último movimento rumo à emersão da MSis ATITUDES INTOLERANTES ERQUEM MUROS

E IMPEDEM A CONSTRUÇÃO DE PONTES emerge entre as linhas 33 e 37 (ver Excerto 3, abaixo) por meio da repetição e expansão dos VMets muros e pontes (l. 34) e da introdução dos VMets contrastantes vida...que devia ser luz e horizonte sem

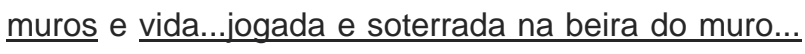
(I. 34 - 36). Atitudes intolerantes como a ganância e o individualismo suplantam atitudes louváveis tais como a valorização da dignidade humana, assim, "erguem mais muros que constroem pontes". O excerto é permeado de movimentos metonímicos e metafóricos, VMets e Metons, que se inter-relacionam 
dinamicamente na consolidação da metáfora em pauta. Uma sequência de Metons "a vida do jovem, da mulher, da criança" (I. 34) que simbolizam segmentos mais fracos da sociedade, geralmente, à mercê de ações arbitrárias de segmentos mais fortes é "jogada e soterrada na beira do muro da intolerância, [...] da indiferença, do individualismo" (I. 35-37). A base cognitiva que licencia tal afirmação de cunho metonímico-metafórico parece estar fundamentada na MC VIDA É OBJETO DESCARTÁVEL. Tais vidas são tolhidas quer literalmente, quer metaforicamente, sem perspectivas da realização de planos e sonhos. Essa situação deplorável é contrastada com aquela que deveria ser uma condição de vida desejável, mais justa, para os fracos "(uma vida) de luz e horizonte sem muros", (I. 35). Porém, tal perspectiva não se realiza devido a atitudes gananciosas e intolerantes dos segmentos dominantes. Interessante o emprego do VMet "(vida de) luz" que é expandido logo a seguir com "horizonte sem muros", o que sugere que a base cognitiva da linha de raciocínio assumida pelo autor seja estruturada a partir da MC primária ENTENDER/CONHECER É VER e do esquema de RECIPIENTE de vez que permitir aos segmentos mais vulneráveis da sociedade acesso à educação e oportunidades de vida mais digna seria dar-Ihes uma "(vida de) luz" (i.e. de entendimento, conhecimento) para sair da condição de ignorância e enxergar "horizonte sem muros" de desigualdade e exploração sociais. Contudo, atitudes intolerantes baseadas na

\section{Excerto3}

\section{TD: Domínio dos ricos sobre os pobres}

33. Estamos num tempo, no Brasil e no mundo, em que a ganância, o acúmulo de bens

34. erguem mais muros que constroem pontes. $\underline{A}$ vida do jovem, da mulher, da criança,

35. dos mais fracos, que devia ser luz e horizonte sem muros, é muitas vezes jogada e

36. soterrada na beira do muro da intolerância, do desrespeito, da indiferenca, do

37. individualismo. ganância, no desrespeito e na indiferença estabelecem bloqueios (muros) e impedem aproximações (pontes) entre fortes e fracos, não permitindo que mentes se abram ao entendimento, Ihes tolhendo assim, a perspectiva de uma vida digna.

\section{Conclusões preliminares}

Apresentamos neste artigo, resultados parciais de uma pesquisa mais abrangente sobre a emergência de sentidos a partir da leitura de gêneros textuais diversos. Num segundo momento ainda futuro da pesquisa ora em andamento, faremos a comparação entre a análise aqui reportada, com as demais, dos exemplares dos gêneros textuais eleitos para investigação, com as falas e produções escritas de alunos do 1․ ao 3․ anos do Ensino Médio, na busca de semelhanças e contrastes relativos à linguagem figurada e sentidos emergentes entre os exemplares dos gêneros analisados e as produções dos participantes da pesquisa.

A análise e resultados parciais aqui apresentados apontam para a emergência no discurso veiculado no artigo de opinião "Os muros", de Selvino Heck, da MSis ATITUDES INTOLERANTES ERGUEM MUROS E IMPEDEM A CONSTRUÇÃO DE PONTES. Entendemos a emergência da linguagem figurada no discurso como decorrente da bidirecionalidade, envolvendo pensamentolinguagem-pensamento. Assim, qualquer emergência discursiva decorre, segundo o entendemos, da interação entre cognição-discurso, sem prevalência de um sobre o outro. As bases teóricas adotadas na pesquisa provêm da Linguística Cognitiva e da Teoria dos Sistemas Dinâmicos Complexos e a abordagem metodológica da Análise do Discurso à Luz da Metáfora, que nos possibilitaram verificar a emergência da metáfora analisada em seus aspectos cognitivo-discursivos. 


\section{Agradecimento}

A pesquisa da qual se originou o presente artigo contou com o apoio financeiro da FAPERGS, por meio do Edital Pesquisador Visitante Sênior 05/2014

\section{Referências}

CAMERON, Lynne. Metaphor in educational discourse. London:Continuum, 2003.

Confrontation or complementarity: Metaphor in language use and cognitive metaphor theory. Annual review of cognitive linguistics, v. 5, 107-135, 2007.

Metaphor shifting in the dynamics of talk, In: ZANOTTO, M.; CAMERON, Lynne.; CAVALCANTI, Marilda. (orgs). Confronting metaphor in use: an applied linguistic approach. Philadelphia: John Benjamins Publishing Company, 2008.

The discourse dynamics framework for metaphor. In: Cameron, L. e Maslen, R. Metaphor analysis. Research practice in applied linguistics, social sciences and the humanities, London: Equinox, 2010.

CAMERON, Lynne. ET AL. The discourse dynamics approach to metaphor and metaphor-led discourse analysis. Metaphor and symbol, v. 24, n. 2, p. 63 - 69, 2009.

CAMERON, Lynne.; LOW, Graham.; MASLEN, Robert. Finding systematicity in metaphor use. In: CAMERON. Lynne.; MASLEN, Robert. Metaphor analysis. Research practice in applied linguistics, social sciences and the humanities. London: Equinox, 2010

CARNEIRO, Monica. Emergência de metáforas sistemáticas na fala de mulheres vítimas diretas de violência doméstica: uma análise cognitivo-discursiva. Tese de doutorado inédita. Universidade Federal do Ceará, 2014

ELMAN Jeffrey. Language as a dynamical system. In: Robert F. Port e T. V. Gelder (Eds). Mind as motion: Explorations in the dynamics of cognition. Cambridge, MA: MIT Press, p. 195-223, 1995.

FAUCONNIER; Gilles; TURNER, Mark. Conceptual integration networks. Cognitive Science, v. 22(2), pp.133-17, 1998.

GATTI, Bernardete. A construção metodológica da pesquisa em educação: desafios. Revista Brasileira de Política e Administração da Educação, v. 28, p. 1334, 2012.

GRADY, Joseph. Foundations of meaning: primary metaphors and primary scenes, 1997. (Tese de
Doutorado inédita) - University of California, Berkeley, 1997

HECK, Silvino. Os muros. Disponível em www.jornaldobrasil.com.br. Acesso em 16/11/2014.

JOHNSON, Christopher. Constructional grounding: The role of interpretation overlap in lexical acquisition. (Tese de Doutorado inédita). University of California, Berkeley, 1999

JONHSON, Mark. The body in the mind: the bodily basis of meaning, imagination, and reason. Chicago and London: The University of Chicago Press, 1987.

LAKOFF. George. Women, fire, and dangerous things: what categories reveal about the mind. Chicago: The University of Chicago Press, 1987.

LAKOFF, George.; JOHNSON, Mark. Metaphors we live by. Chicago: University of Chicago Press, 1980.

Philosophy in the flesh. New York: Basic Books, 1999. $625 \mathrm{p}$

LARSEN-FREEMAN, Diane; CAMERON, Lynne. Complex systems and applied linguistics. Oxford: Oxford University Press, 2008. 300 p.

MACEDO (PELOSI), Ana. C. P. S. de. A psycholinguistics analysis of the metaphor DIFFICULTIES ARE WEIGHTS. Linguagem em Discurso, v. 7, n. 3, 2007.

MARCUSCHI, Luiz Antonio. Gêneros textuais: o que são e como se constituem. Universidade Federal de Pernambuco, UFPE. Recife: PE, 2000.

NARAYANAN, Srinivas. Moving right along: a computational model of metaphoric reasoning about events. (Tese de doutorado inédita). International Computer Science Institute, University of California, Berkeley, 1997.

STEELS Luc. Language as a complex adaptive system. Proceedings of the $6^{\text {th }}$ International Conference on Parallel Problem Solving from Nature. London: Springer Velag, p. 17 - 26, 2000.

THELEN, Esther.; SMITH, Linda. A dynamic systems approach to the development of cognition and action. Cambridge, MA: MIT Press, 1994.

THELEN, Esther; SCHÖNER, Gregor; SCHEIER, Christian; SMITH, Linda. The dynamics of embodiment: A field theory of infant perseverative reaching. Behavioural and brain sciences, v. 24, p. 1 86,2001

TURNER, Stephen. Brains/practices/relativism: Social theory after cognitive science. Chicago e London: University of Chicago Press, 2002.

VAN GEERT Paul. A dynamics system model of basic developmental mechanisms. Piaget, Vygotsky and Beyond. Psychological review, v. 105, p. 634-677, 1998 